\section{Gategory}

\section{Synthesis of}

Heterocycles

\section{Key words}

tetrahydrofurans

carboetherification

radical alkylation

copper catalysis

SYNFACTRthen

Y. MILlER, L. MIAO, A. S. HOSSEINI, S. R. CHEMLER* (THE STATE UNIVERSity OF NEW YORK AT BUFFALO, USA)

Copper-Catalyzed Intramolecular Alkene Carboetherification: Synthesis of Fused-Ring and Bridged-Ring Tetrahydrofurans

J. Am. Chem. Soc. 2012, 134, 12149-12156.

\title{
Cu-Catalyzed Carboetherification Approach to Polycyclic Tetrahydrofurans
}

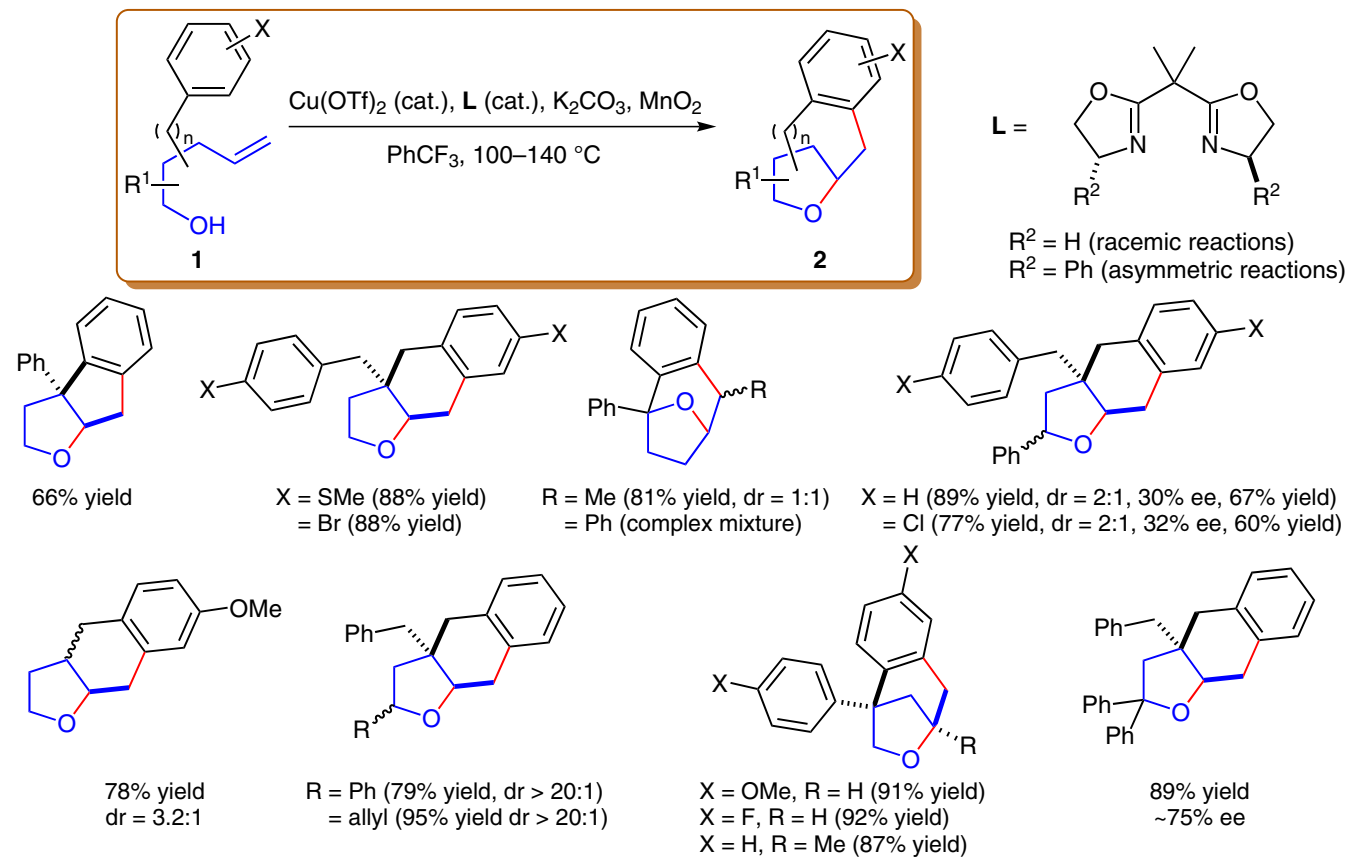

Significance: The Cu-catalyzed conversion of 4penten-1-ols bearing benzyl or phenyl substitution (1) into polycyclic tetrahydrofurans $\mathbf{2}$ is reported. Depending on the substitution pattern in $\mathbf{1}$, three distinct core structures (fused and/or bridged) were synthesized. Substituents tolerated in this process included $\mathrm{Br}$ and SMe, but unsaturated and/or strongly Lewis basic functional groups were absent from the study. Cu(2-ethylhexanoate) ${ }_{2}$, with or without a bisoxazoline ligand, was occasionally used in place of $\mathrm{Cu}(\mathrm{OTf})_{2}$ to obtain better diastereoselectivity. Several catalytic asymmetric reactions were demonstrated, but ee's ranged from $<5 \%$ to ca. $75 \%$. A procedure for hydroetherification was also reported. The products are notable for their complexity and similarity to several bioactive natural products such as bruguierol C (L. Han et al. Planta Med. 2005, 71, 160).

SYNFACTS Contributors: Victor Snieckus, Benjamin N. Rocke (Pfizer) Synfacts 2012, 8(10), $1070 \quad$ Published online: 19.09.2012 Dol: 10.1055/s-0032-1317291; Reg-No.: V11612S
Comment: Mechanistic evidence suggests that the reaction proceeds by oxycupration of the olefin $\mathbf{1}$, radical alkylation of the benzene ring, and oxidation to the products $\mathbf{2}$. The low enantioselectivity observed for the bridged-ring products was rationalized by a proposed THF ring opening-unselective closing cascade prior to the relatively slower radical alkylation step. The reported reaction bears similarity to Pd-catalyzed carboetherification (e.g., R. Zhu, S. L. Buchwald Angew. Chem. Int. Ed. 2012, 51, 1926); notably, $\beta$-hydride elimination does not occur under Cu catalysis, allowing expanded scope in the present case. Radical alkylation is well known in the context of the Minisci reaction (see Review below), suggesting that further complexity in the product structures might be possible.

Review: M. A. J. Duncton Med.Chem.Comm. 2011, 2, 1135-1161. 